\title{
Sheikh Bin Wan Ismail Wan Abdul Qadir (d. 1965) And His Efforts in the Field of Islamic Faith
}

\author{
${ }^{1}$ Mujahid Mustafa Bahjat \\ 2Mosidi Sally Bin Saleh
}

1 University of Malaya

2University of Malaya

*Email: mujahid.mustafa@gmail.com

\begin{abstract}
Wan Ismail Shaikh Abdul Qadir was one of the Ulema, he known to struggle in spreading Islamic Aqedah and development in the Patani region in particular and generally in Malay region, this study will provide an overview of his life and contribution to science, and also the study of the struggle to spread knowledge in the Islamic faith. One of the relics of his work is "Bakurah ألأمان ي for the Layman Patani" is the greatest work of his in the Islamic Aqedah Science until recently used as a guide and reference in the study of science aqidah in the Malay region.
\end{abstract}

Keyword:Islamic Aqidah; Malay Region; Aqidah Science

1 إ مقدمة

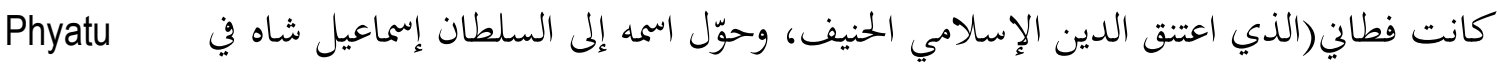
منطقة إسلامية مستقلة يقطنها المسلمون من العنصر الملايوي، ويحكمون أنفسهم (Antira Ahmad Fathy, بأنفسهم تحت ظل الإسلام، ودخلت الثقافة الإسلامية بلاد فطاني بدخول الإسلام، وانتشرت المساجد في أرجاء البلاد، وأسهمت المساجد في فطاني إسهاماً عظيماً في نشر العلوم الإسلامية وثقافتها، وكانت الإطار بار الأساسي لنشر العقيدة الإسلامية بين الشعب. ومن المسلم به أن تاريخ التعليم في العالم الإسالامي على وجه العموم وفي فطاني على وجه الخصوص كان منذ البداية قد ارتبط ارتباطاً وثيقاً بالمسجد لأن الدراسات آنذاك كانت دينية خالصة تعنى بشرح وتوضيح تعاليم الإسلام وأحكامه، وقد أجمعت المصادر والمراجع على أن المسجد أهم مكان لنشر العلوم والثقافة الإسلامية إلى جانب كونه مكاناً للعبادة وداراً للاحتكام وملتقى لإِى للتشاور، وإلى جانب المسجد وحلقاته في فطاني، كانت الدراسة تجري في أماكن أخرى تمثلفي (Chapakia).

$$
\begin{aligned}
& \text { أولاً: في كتاتيب الأطفال، وهذه الكتاتيب كانت تقوم في الغالب بجوار المسجد، وقد أسهمت إسهاماً } \\
& \text { معيناً وهاماً في إعداد ذوي المؤهلات الدينية، وهذا النوع من التعليم يخصص للأطفال الذين يبدأون } \\
& \text { دراستهم من تعلم الحروف العربية قراءة وكتابة حتى يمكنهم تلاوة القرآن بالعربية بلغة صحيحة، وأيضاً تعلم } \\
& \text { الحروف الجاوية، وفضلاً عن ذلك يدرسون الأحكام الإسلامية الأساسية. }
\end{aligned}
$$


ثانياً: دور الشيوخ والعلماء، ويأتي بعد ذلك دور الشيوخ والعلماء حيث كانوا يجعلون بيوت سكنهم أماكن للتدريس، يقصدهم العامة والخاصة. وهكذا كانت الدور من جهة والكتاتيب وحلقات المساجد من جهة أخرى المؤسسات الأولى عند المسلمين في فطاني لنشر العلم والمعرفة.

وأيضاً مما يجدر الإشارة هنا إلى أن فطاني تعد من أشهر مراكز الثقافة والعلم في منطقة جنوب شرق آسيا، وكانت ملتقى العلماء والطلاب ومهد المدارس، حيث نشأت فيها مراكز علمية عرفت لدى سكان هذه البلاد بـ "فندوق" من أجل زرع المفاهيم الإسلامية والحماسة الدينية، يقصدها الطلاب من الدول المحاورة لما من كلنتان وتربحانو وقدح وفاهانج وغيرها من ماليزيا الاتحادية ومن جمفا وغيرها. وفي الحقيقة إن نظام "فندوق" التعليمي قد أسهم مساهمة كبيرة ناجحة في خدمة الإسلام والمسلمين وهو أصبح سائداً في دول الملايو ولايزال باقياً فيها إلى يومنا هذا. وهومشعل العلم الحقيقي في البلاد، ويمكننا أن نقول: لولا هذه المدارس (فندوق فطاني) لما وجد فيها أي أثر علمي يذكر، لأنه عن طريقها خرج علماء وفقهاء ودعاة وأئمة وخطباء وأساتذة كتبوا وألفوا ودرسوا بجهودهم وحملوا مشعل العلم في بلادهم في وقت عمّ الجهل والأمية أرجاء منطقتها. ويرى الدكتور عبد الغني يعقوب في مقالته:من معالم التاريخ السياسي والعلمي الإسلامي في فطاني دار السلام، أن أسباب شهرة فطاني بمهمتها العلمية والحضارية والفكرية لقيام ديارها على ثلاثة

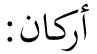

1- علماء تقليديين بقوا في البلاد حيث أنشأوا المدارس والمراكز العلمية على الطراز القديم.

2- علماء هاجروا بعقولمم المستنيرة إلى مكة المكرمة حيث تربوا وترعرعوا فيها وألفوا الكتب الدينية ثم أرسلوا إلى أهليهم في أوطاهم بتلك المؤلفات العلمية الثمينة، وقد أثرت هذه الكتب العلمية في عقول الفطانيين ومن جاورهم من الملايويين فكرياً وثقافياً.

3- علماء حصلوا على الدرجات العلمية من الجامعات الإسلامية في العالم الإسلامي، ثم رجعوا إلى قراهم وفتحوا المدارس الدينية الحديث (عبد الغني يعقوب, 2006). ب. المبحث الأول: دراسة حياة الشيخ وان إسماعيل بن وان عبد القادر الفطاني

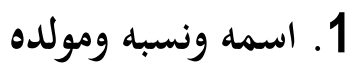

إن فطاني قد أبخبت رجالاً يندر مثلهم في الذكاء وخصوبة الفكر والابتكار العلمي وكثرة المؤلفات والانتاج، ومن الجفاء أن تبقى هذه المنطقة الغنية برجالها وأعمالها وماضيها وحاضرها بجهولة عند أصدقائها في الخارج مطمورة في صفحات التاريخ، ومن أشهر هؤلاء العلماء الذين كانت لهم المساهمة الكبيرة في نشر العلوم 
الدينية وخصوصاً علم العقيدة في فطاني والأثر العظيم في إرساء دعائم الإسلام بهذا الجزء من العالم الإسلامي: الشيخ وان إسماعيل بن وان عبد القادر رممهما الله

فاسمه الكامل: هو الشيخ وان إسماعيل بن وان عبد القادر( الثيخ وان عبد القادر 1985) بن وان

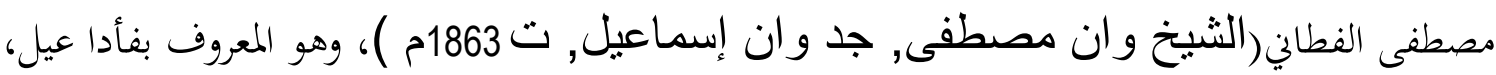
ولد رحمه الله في قرية بندانج دايا فطاني دار السلام سنة 1300 هـ الموافق 1882م.

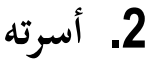

نشأ الشيخ وان إسماعيل رحمه الله في بيئة علمية صالحة، وأسرة الشيخ أسرة دين وفضل خير، وبيته بيت علم المان

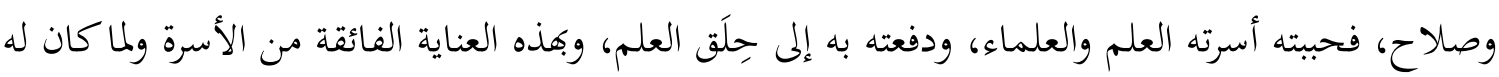

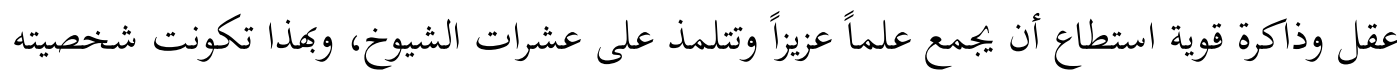

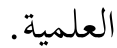

وفي الحقيقة إن أسرة الشيخ من الأسر التي خرج منها كثير من العلماء والفقهاء، وخاصة أسرته من جهة الأب، فكان لجده - الشيخ وان مصطفى - أربعة أولاد، وهم: الشيخ وان محمد زين (ت 1908م)، والشيخ عبد اللطيف، والشيخ عبد القادر (والده) والشيخ داود (ت .(2002,Ahmad Fathy)

ولا نبالغ إذا قلنا: إن الشيخ وان إسماعيل رحمه الله قد توافرت فيه أمور أساسية في تعلمه وطلبه للعلم وهي

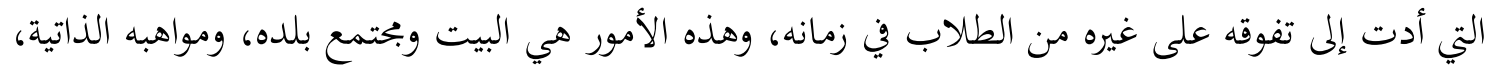

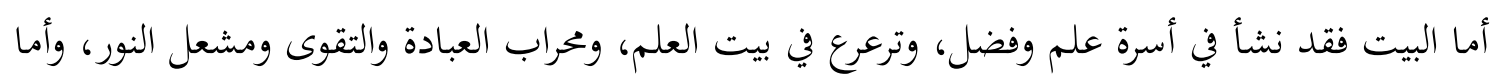

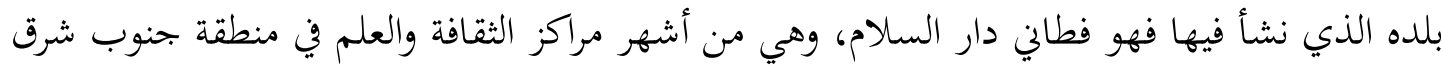

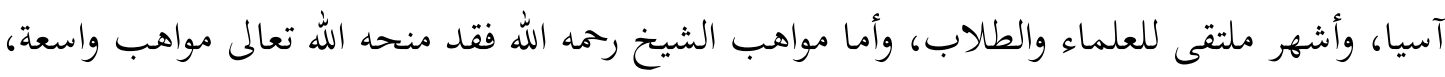
فقد ظهرت عليه النجابة والتفتح والذكاء منذ حداثنه.

3. - نشأته الشخصية والعلمية

عاش الشيخ وان إسماعيل رحمه الله من سنة أم 1882م- 1965م، فكان عمره عند وفاته ثلاثة وثمانين عاماً، قضى منها ثلاث عشر سنة في مسقط رأسه، وفي المرحلة الأولى لحياته العلمية تلقى الشيخ رممه الله العلوم

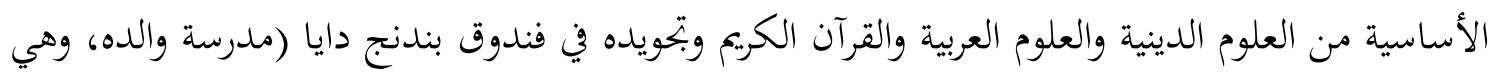


أقدم المؤسسات التعليمية التقليدية وأشهرها في ذلك الوقت)، وتربى فيها على يد والده الذي كان يعد من أحد العلماء البارزين في المنطقة، وأيضاً على يد الشيخ عبد الصمد بن محمد سمان النوفي الفطاني، وقد ساهما مساهمة فعالة في تكوين شخصية الشيخ علمياً وثقافياً، ولا شك أن هذا العلم وهذه الصفات التي اتصف بها والده وشيخه وأسرته كان لما أثر قوي في توجيه الشيخ وتنشئته النشأة الطيبة، وخاصة في مرحلة قبل البلوغ.

وفي سنة 1895م، رحل الشيخ وان عبد القادر إلى مكة المكرمة لأداء العمرة والحج، وأخذذ ولدَه وان إسماعيل معه وهو ابن ثلاثة عشر عاماً، وبعد الانتهاء من أدائهما، ترك الشيخ ولده ليبقى بمكة مع عمّيه الشيخ محمد زين والشيخ داود رحمهما الله اللذين اتخذا مكة مكان إقامتهما، وفي مكة بدأ الشيخ وان إسماعيل يتلقى العلوم وأخذها من العلماء الملايويين الذين استوطنوا مكة من أجل التعمق العلمي والتفقه في الدين، وكذلك حضر حلقات العلماء العرب بمكة المكرمة.

أفاد أصحاب التراجم بأن الشيخ وان إسماعيل تتلمذ على كثير من الشيوخ والعلماء من فطاني والعرب بمكة المكرمة، وقرأ على عدد منهم، ومن أشهرهم, (Abdullah dan Fathy, 1996). - أبوه الشيخ وان عبد القادر (صاحب فندوق بندنج دايا) أخذ عنه الشيخ العلوم الدينية الأساسية. - الشيخ عبد الصمد بن محمد سمان النوفي الفطاني، أخذ عنه الشيخ العلوم الدينية الأساسية.

$$
\begin{aligned}
& \text { - الشيخ وان حمد زين الفطاني (عمه) } \\
& \text { - الشيخ فأجيك داود (عمه ووالد زوجته) } \\
& \text { - الشيخ وان أحمد بن حممد زين (ابن عمه) } \\
& \text { - الشيخ نوح بن عبد المجيد } \\
& \text { - الشيخ غختار عطارد بوكور - }
\end{aligned}
$$

- وغيرهم من المشايخ الفضلاء، أخذ عنهم العلوم الدينية الأساسية منها: القرآن الكريم وبتويده، والفقه

$$
\text { الشافعي، وعلم أصول الدين، والنحو والصرف وغيرها. }
$$

وبعد هذه الرحلة العلمية الطويلة، انتقل الشيخ وان إسماعيل إلى رحة الله في 3 نوفمبر 1965م بمكة المكرمة. 
في هذا المبحث، نود أن نشير إلى جهود الشيخ وان إسماعيل رمهه الله في تدريس العلوم الدينية وتصنيف

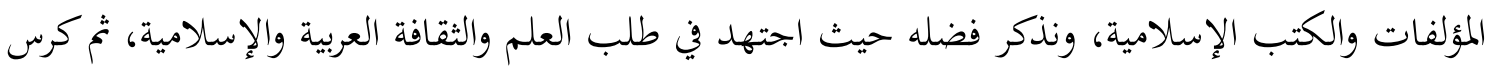
حياته لنشر الثقافة الإسلامية وعلومها.

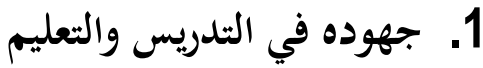

اختار الشيخ وان إسماعيل رممه الله مكة المكرمة مكان إقامته - كما فعل ذلك عماه الشيخ وان محمد زين

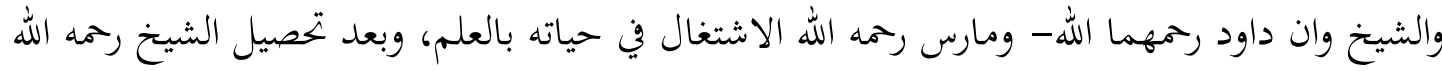

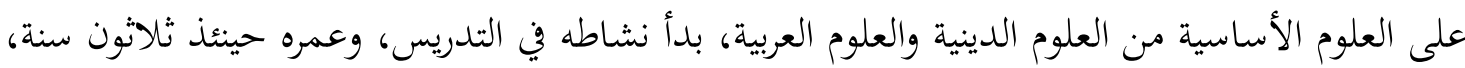
وكان رممه الله يهتم اهتماماً كبيراً بالتدريس والتربية والوعظ، وكانت مواظبته على التدريس والوعظ والتربية

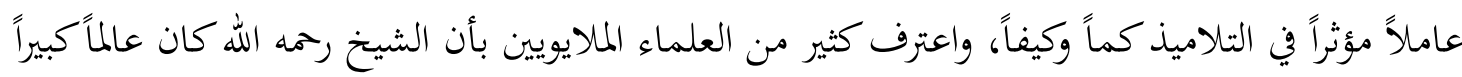

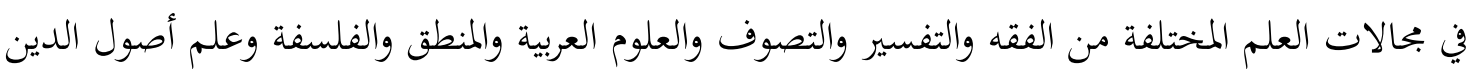
وغيرها. (- n

كان رممه الله ينظم جل أوقاته -في النهار والليل - للتدريس في بجالات علمية خختلفة، في أصول الدين،

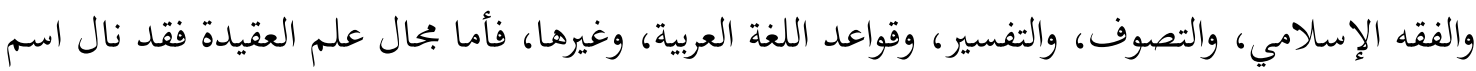

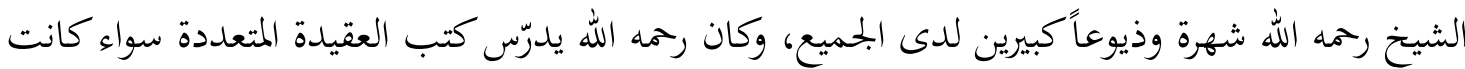

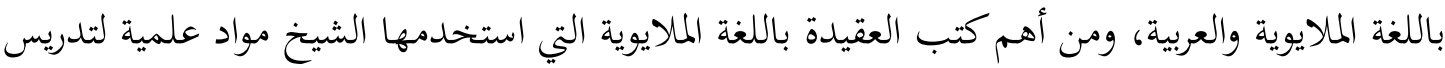

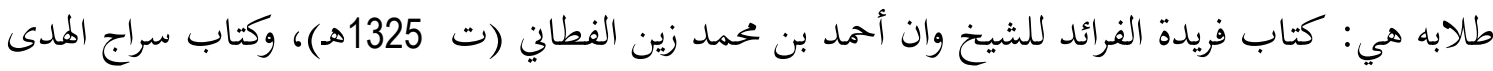

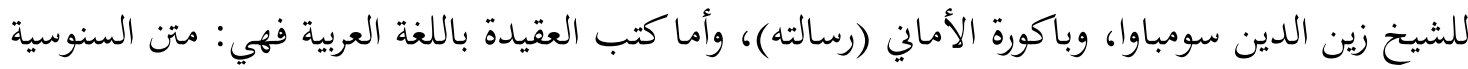

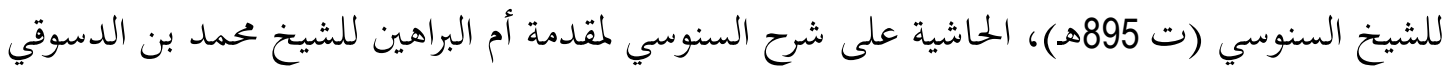
(ت1230هـ)، متن جوهرة التوحيد للشيخ إبراهيم بن حسن اللقاني (ت 1041هـ)، تحفة المريد على جوهرة

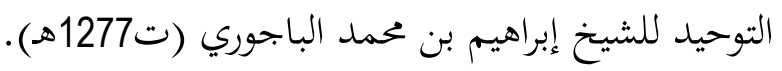

ويف بحال الفقه الإسلامي فكان يدرّس كتاب فتح الوهاب بشرح منهج الطلاب للشيخ أبي يهيى زكريا

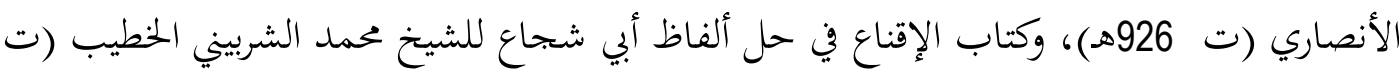

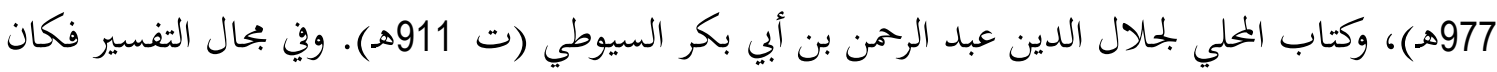

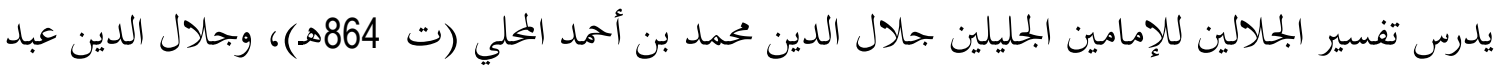

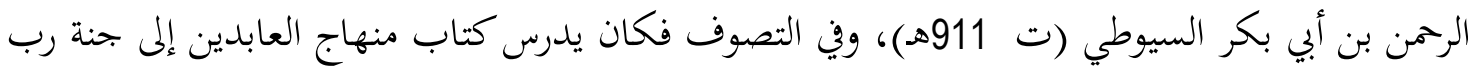
العالمين للشيخ داود بن عبد الله الفطاني (ت 1263 1ه)، كما كان يدرس طلابه قواعد اللغة العربية مثل بن 
حاشية على شرح الفاكهي لقطر الندى للشيخ ياسين بن زين الدين الشافعي (ت 1651م)، وشرح ابن

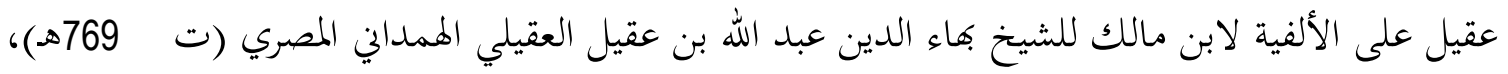

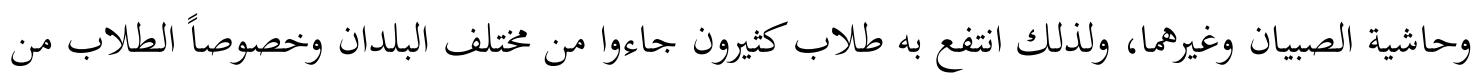

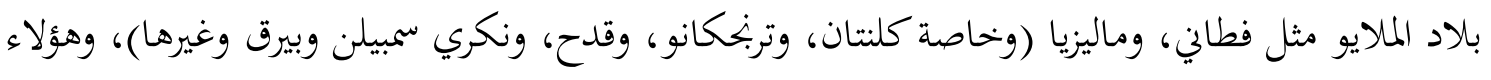

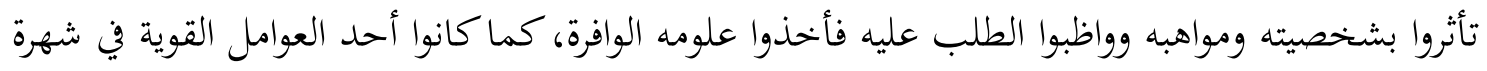

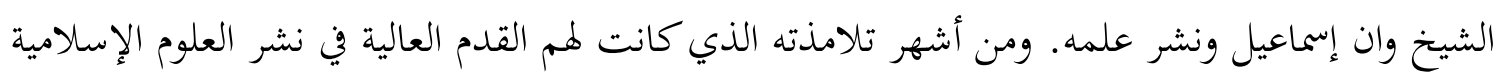

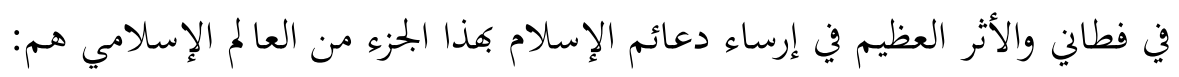

- الشيخ عبد الرممن دالا صاحب فندوق دالا (فطاني)(الثيخ عبد الرحمن بن محمد أرشد1976) - الشيخ حسن صاحب فندوق مككول(Fathy, 1996), - الشيخ أحمد بن عبد الوهاب صاحب صاحب فندوف فيدوق فوسان, (Fathy, 1996)

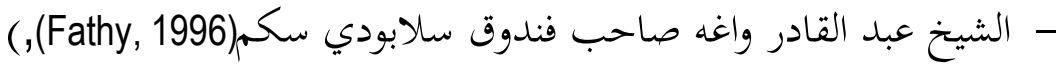

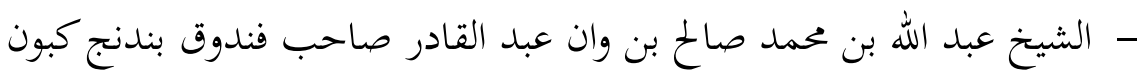

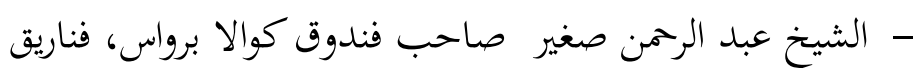

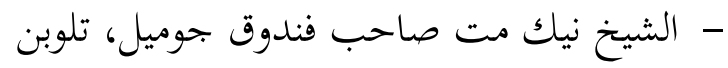

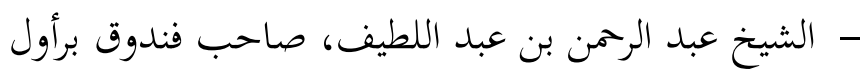

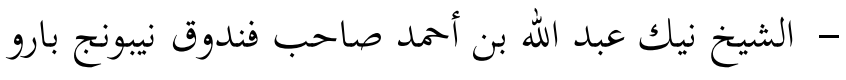
- الشيخ يوسف مؤسس فندوق ملايو بانكوك جالا

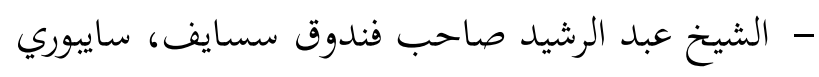

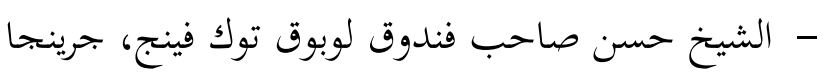

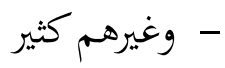

2. ومن أشهر تلامذته خارج فطاني

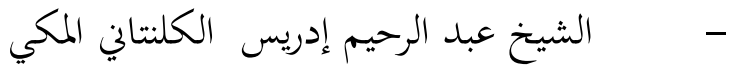

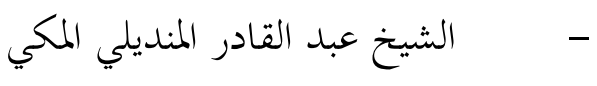

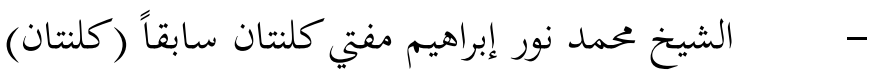

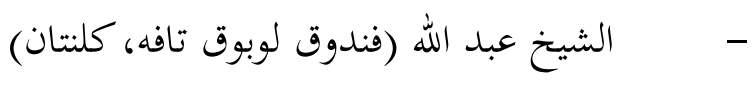

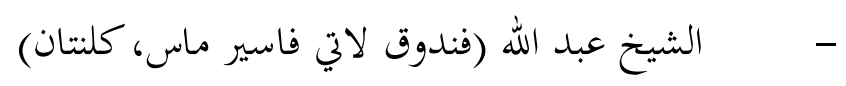

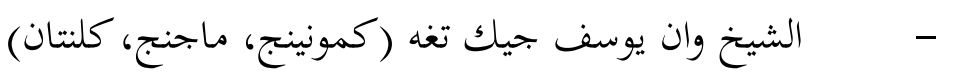




$$
\begin{aligned}
& \text { - - - مالشيخ عبد الرحمن بن سليمان (فندوق سوبجاي دوريان، كوالاكراي، كلنتان) }
\end{aligned}
$$

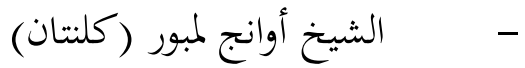

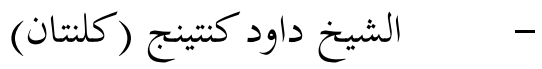

$$
\begin{aligned}
& \text { - - - - - إسيخ إسماعيل أحمد إمام مسجد ولاية نكري سمبيلن (نكري سمبيلن) } \\
& \text { - }
\end{aligned}
$$

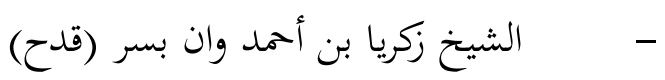

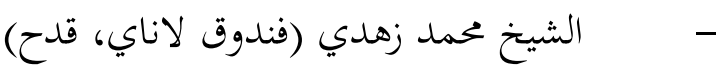

$$
\begin{aligned}
& \text { - - مالشيخ وان عبد الرحمن لونج (تربخكانو) }
\end{aligned}
$$

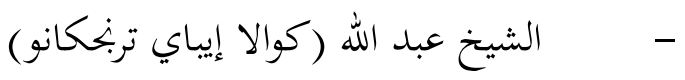

$$
\begin{aligned}
& \text { - ميرهم كثير }
\end{aligned}
$$

وهنا يمكننا أن نلخص القول بأننا لا نبالغ إذا قلنا: إن الشيخ وان إسماعيل رحمه الله ممن أسهم إسهاماً كبيراً في نشر العلوم الدينية في فطاني خاصة وبلاد الملايو عامة، وخرّجت حلقته العلمية بمكة المكرمة كثيراً من طلاب العلم، وذلك لأن كثيراً منهم قد أقاموا وفتحوا وأسسوا مؤسسات دينية ومراكز علمية في فطاني دار السالام، وما جاورها من البلدان. وجديد بالذكر هنا أيضاً إلى أن في المنتصف الثاني من القرن التاسع عشر الميلادي وأوائل القرن العشرين، وصل نظام فندوق (المدارس التقليدية) في فطاني دار السلام إلى عصره الذهبي حيث ظهر في هذه الحقبة كثير من العلماء الذين واصلوا دراستهم بمكة المكرمة، وبعد ما حصلوا على قسط من العلم، رجعوا إلى البلاد (فطاني) فبدأو بفتح المدارس وتعليم الناس أمور دينهم وغرس بذور حب الدين في نفوسهم، وهذا يعني أنه من خلال هذه الحقبة بدأت الصورة تتضح أكثر وأكثر عن وجود فندوق (المدارس التقليدية) في فطاني دار السلام، ومن أشهر هذه المؤسسات وأكبرها: فندوق دالا

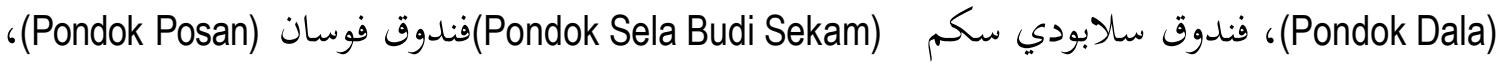
فندوق بندنج بادنج (Pondok Bendang Badang)، فندوق مككول (Pondok Makngul)، ومما لا نستطيع أن ننساه بأن أكثر شيوخ هذه المؤسسات الدينية كانوا ممن درسوا وتتلمذوا على يد الشيخ وان إسماعيل بمكة

\section{3. جهوده في التصنيف والتأليف}

قدر الله تعالى لأرض فطاني أن تخرج عدداً من العلماء الذين كثرت مؤلفاقم وانتشرت في دول عديدة من

أرخبيل الملايو، ومما يدل على الأثر الفعال لهم في نشر الثقافة الإسلامية في بلادهم تأليفهم - بعد ما

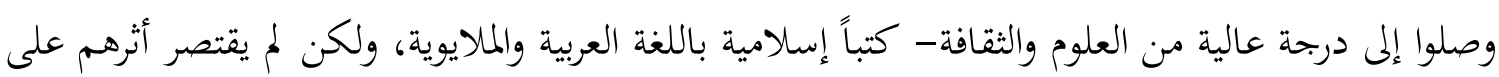


التأليف فقط بل أقدموا على ترجمة أمهات الكتب العربية الإسلامية إلى اللغة الملايوية التي تحوى بين جنباتا

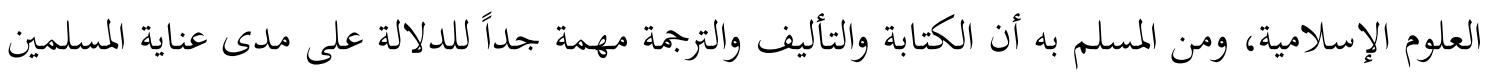
بالعلوم الإسلامية واللغة العربية. وهذا واضح جلي إذا درسنا تاريخ الدعوة الإسلامية في فطاني ومساهمة الداهي

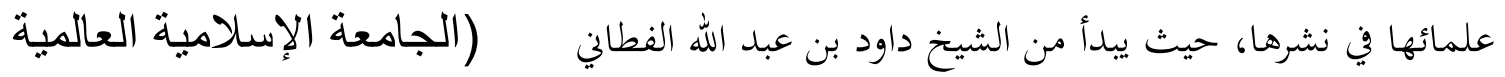

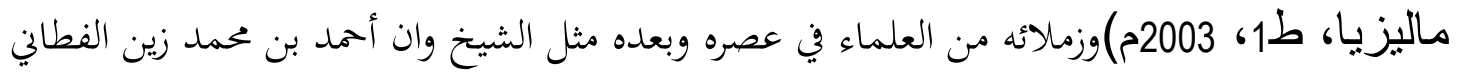

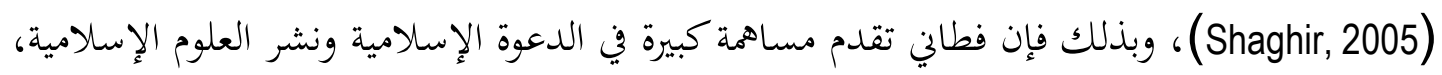

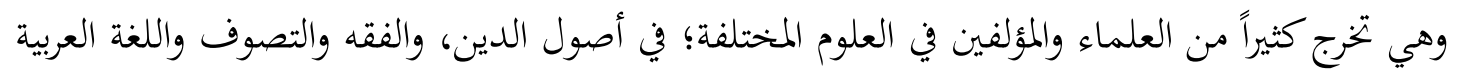

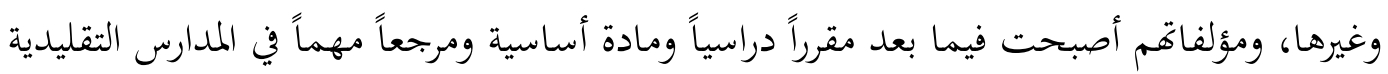
(فندوق) منذ القرن التاسع عشر الميلادي إلى يومنا هذا.

علماء فطاني كثيرون، منهم من أعطي القدرة على التأليف والكتابة، فترك لنا مؤلفاته، ومنهم من لم يجد

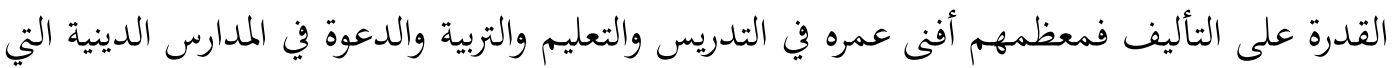

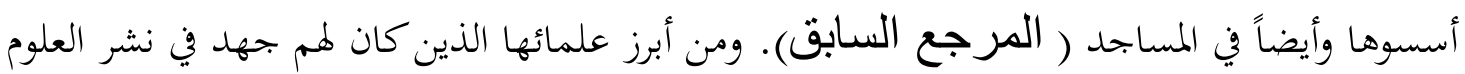

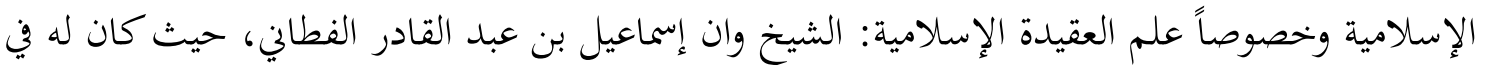

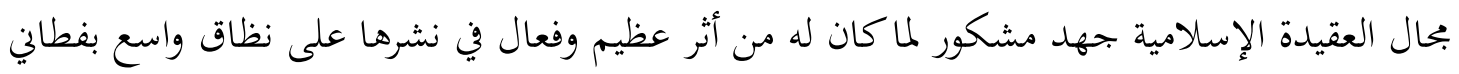

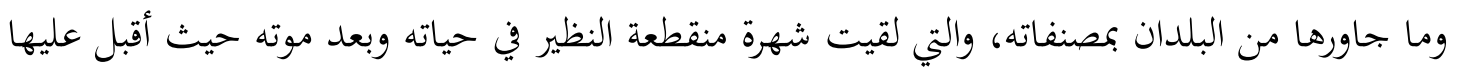

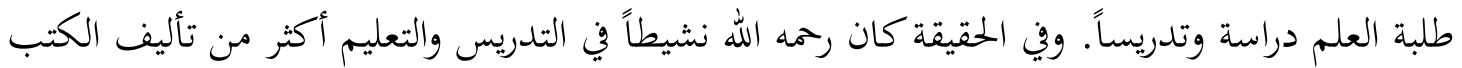

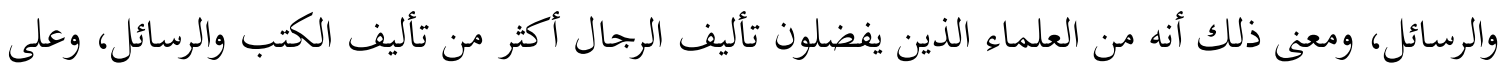

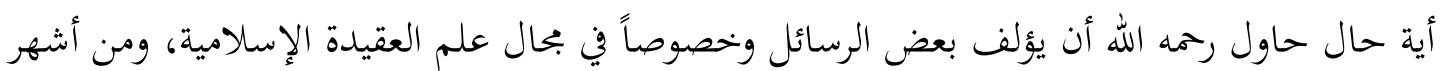
رسائله:

\section{- - اكورة الأماني لإشارة عوام أهل الفطاني}

أبخز الشيخ وان إسماعيل بن عبد القادر الفطاني تأليف هذه الرسالة ليلة السبت 14 رجب 1336 هجرية،

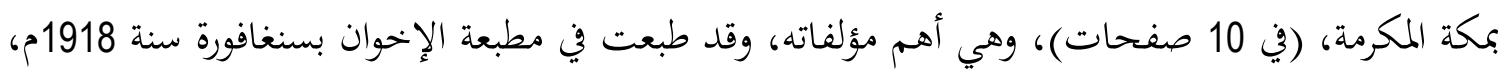

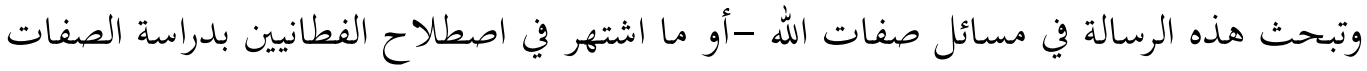

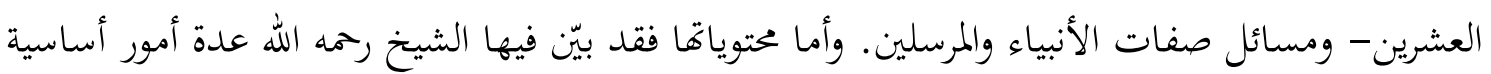

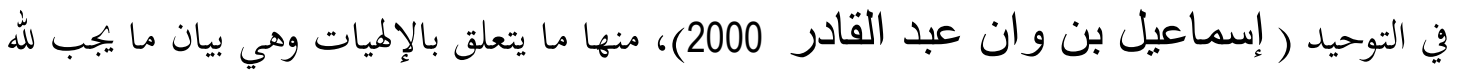

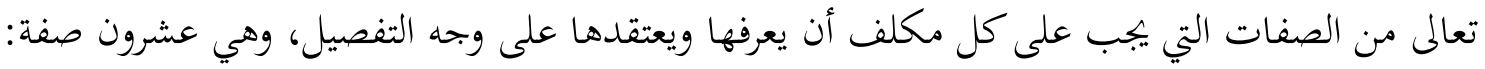

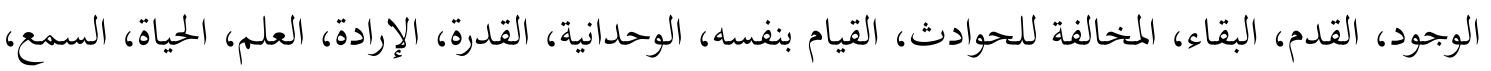


البصر، الكلام، كونه تعالى قادراً، كونه تعالى مريداً، كونه تعالى عالماً، كونه تعالى سميعاً، كونه تعالى بصيراً،

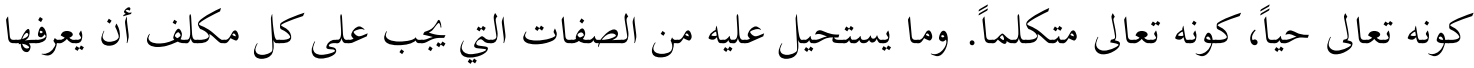

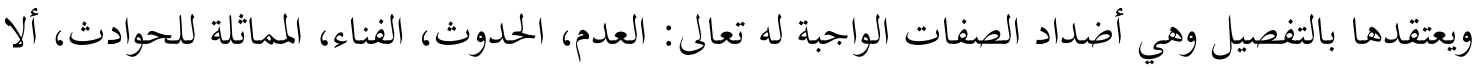

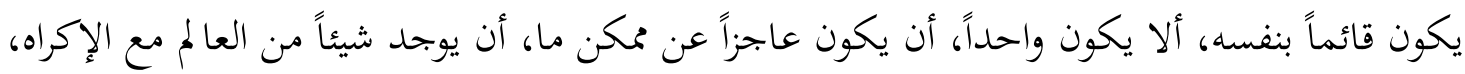

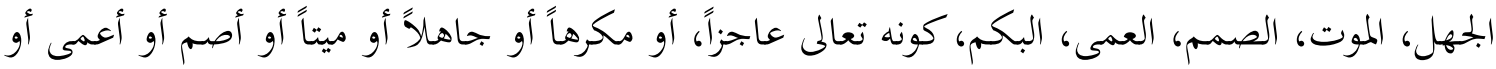

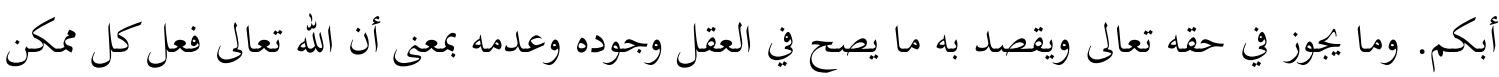
وتركه، فلا يجب عليه شيء من الممكنات كما لا يستحيل.

ومنها ما يتعلق بالنبوات وهي بيان ما يجب للرسل من الصفات التي يجب على كل مكلف أن يعرفها

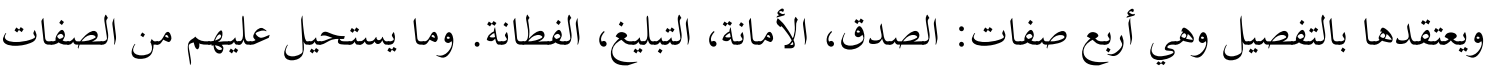

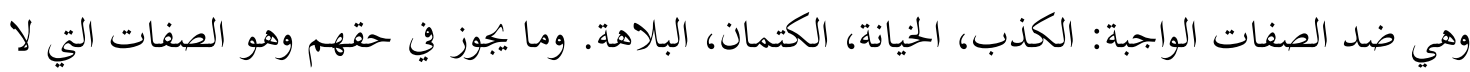

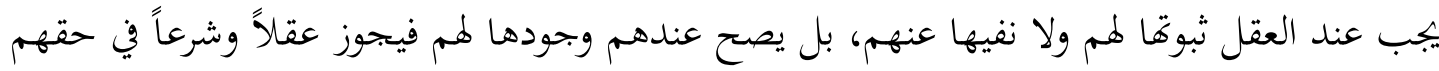
أ.جمعين.

وأما منهج الشيخ في كتابة هذه الرسالة فهو يتمثل في الأمور الآتية:

- تعريف الصفات الواجبة لله عز وجل، والاستدلال على وجوب اتصافه عز وجل بهذه الصفات، وبيان

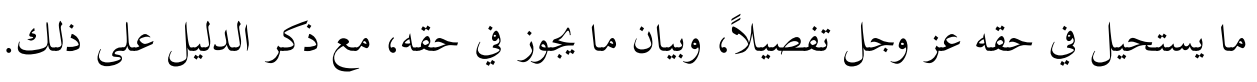

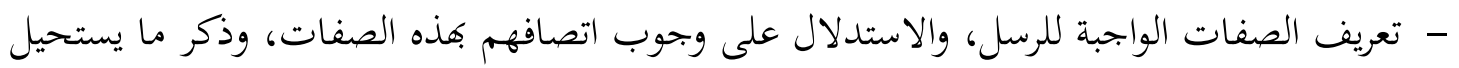

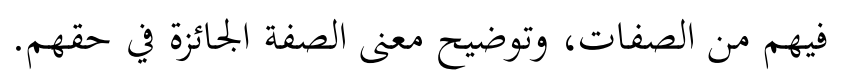

تعد هذه الرسالة من المقررات الدراسية الأساسية في الحلقات العلمية بالمؤسسات التعليمية التقليدية (نظام

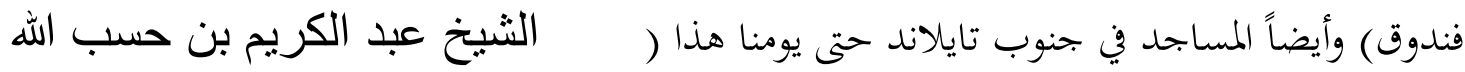
2008,عبد الرحمن 2009)، قال الأستاذ أحمد فتحي في مقالته إسهامات علماء فئاء فطاني في التربية الإسلامية: إن دراسة علم العقيدة الإسلامية في المؤسسات التعليمية التقليدية (نظام فندوق) في الغالب أن

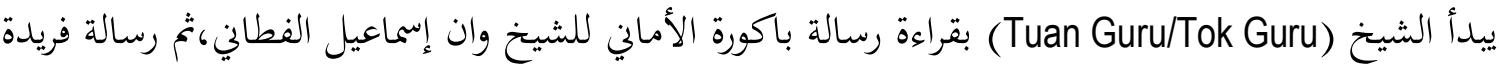

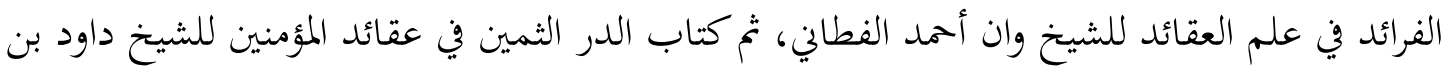

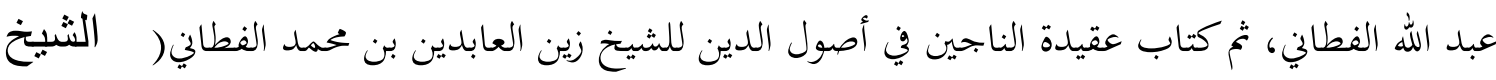

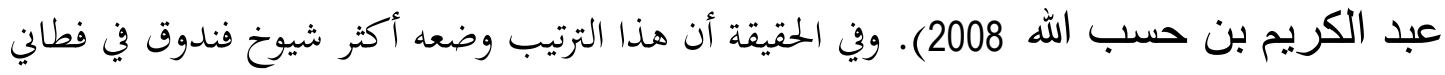
(الثيخ عبد الكريم بن حسب الله 2008). 


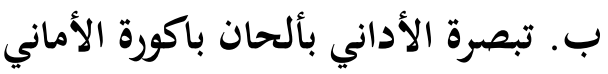

وهي شرح رسالة الباكورة، وفقد أبخز الشيخ وان إسماعيل رمه الله شرحها في يوم الخميس 25 حرم 1358هـ، بمكة المكرمة (في 30 صفحة)، وطبعت هذه الرسالة في مطبعة فطاني فريس، بفطاني دار السلام سنة

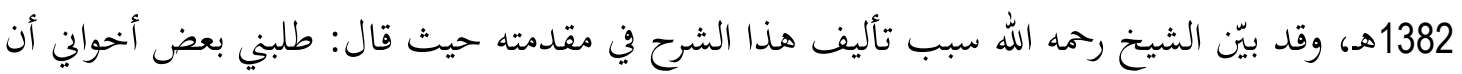

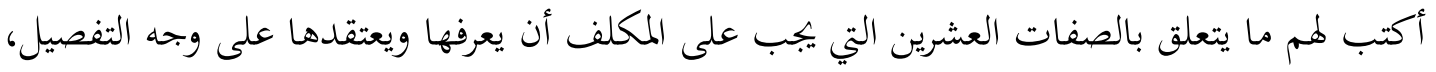
وسمّى هذا الشرح بتبصرة الأداني بألحان باكورة الأماني (إسماعيل بن بن عبد القيل القادر الفطاني 1382).

\section{ج. إيضاح المرام لتحقيق سبل السلام}

لم بند هذه الرسالة، ولكن بند شرحها لتلميذه الشيخ عبد القادر بن إسماعيل السنوي الفطاني، وهو

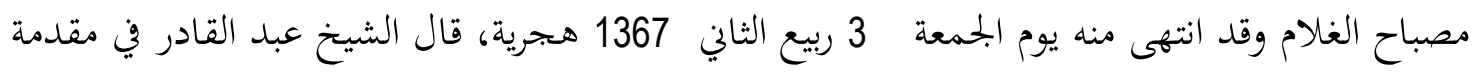

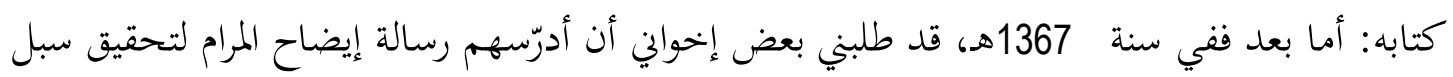

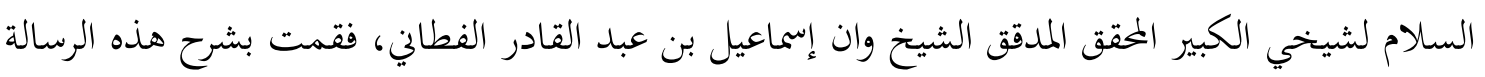

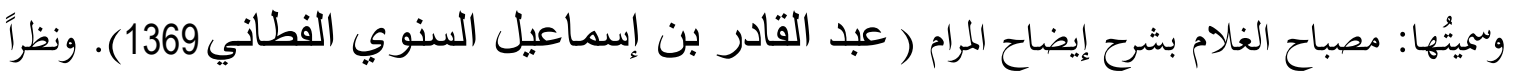

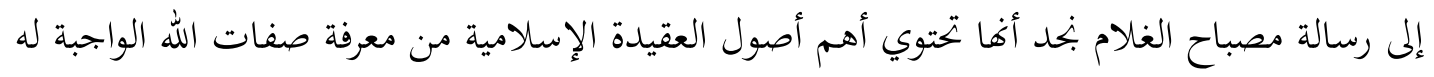
تفصيلاً، والصفات المستحيلة عليه والصفة الجائزة في حقه، وأيضاً معرفة صفات الأنبياء والمرسلين.

وقيل إن الشيخ وان إسماعيل قام بشرح رسالة فريدة الفرائد في علم العقائد للشيخ وان أحمد بن محمد زين

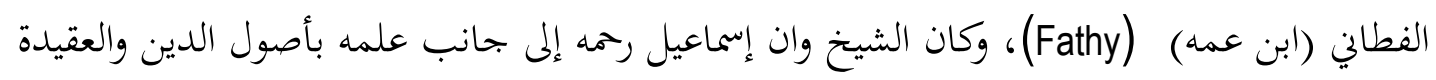

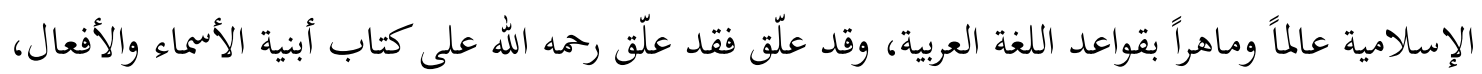

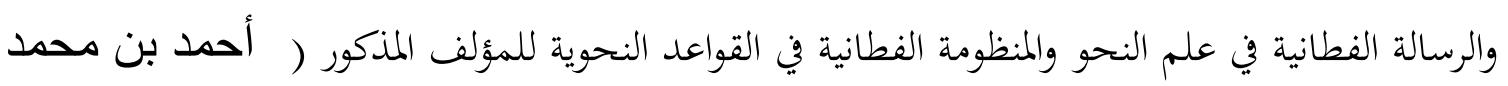
زين الفطاني).

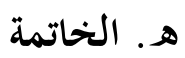

فإن الباحث في فاية هذه الورقة المتواضعة يشكر الله تعالى على ما أنعم عليه بإكمالها، وهنا يذكر أهم

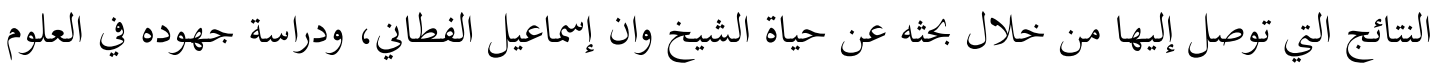

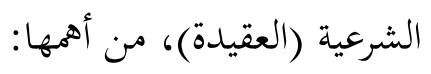


- ـ ولد الشيخ في قرية بندنج دايا، فطاني، ونشأ في بيئة علمية صالحة، ودرس العلوم الدينية عن والده وشيوخه في القرية، ثم انتقل مع أسرته إلى مكة المكرمة، وتفرغ لطلب العلم وأحذ العلوم الإسلامية

$$
\text { والعربية عن علماء فطاني وعلماء العرب الموجودين هناك. }
$$

- وبعد تحصيل العلوم، مارس الشيخ رحمه الله في حياته الاشتغال بالعلم في بحال التدريس والتعليم، واتنفع به طلاب كثيرون، وعكف على التأليف والتصنيف، وكان يحتل مكانة علمية واجتماعية مرموقة بين علماء عصره ولدى طلاب العلم وخصوصاً الطلاب من جنوب شرق آسيا لأنه شيخ مشهور يعقد الحلقة العلمية في بيته والمسجد الحرام بمكة المكرمة. - كان رحمه الله يساهم مساهمة كبيرة في نشر العلوم الدينية والثقافة الإسلامية في فطاني وما جاورها، لأن كثيراً من تلامذته قد فتحوا وأسسوا مؤسسات دينية ومراكز علمية، وخاصة في أواخر القرن التاسع عشر وبداية القرن العشرين الميلادي، في حين وصل نظام فندوق في فطاني إلى عصره الذهبي. - حلف الشيخ رحمه الله لطلاب العلم والعلماء تراثاً علمياً وخاصة في بجال علم العقيدة الإسلامية، ورسالة باكورة الأماني لإشارة عوام أهل الفطاني، وتبصرة الأداني بألحان باكورة الأماني، وإيضاح المرام لتحقيق سبل السلام أهم رسائله العقدية.

وأخحيراً ندعو الله أن يرحم الشيخ وان إسماعيل رحمة واسعة ، ويجزيه عن المسلمين خير الجزاء، ويحشرنا وإياه مع الذين أنعم الله عليهم من النبيين والصديقين والشهداء والصالحين وحسن أولئك رفيقاً، وصلى الله على نبينا محمد وعلى آله وصحبه أجمعين، سبحان ربك رب العزة عما يصفون وسلام على المرسلين والحمد لله رب العالمين. 


$$
\text { المصادر والمراجع }
$$

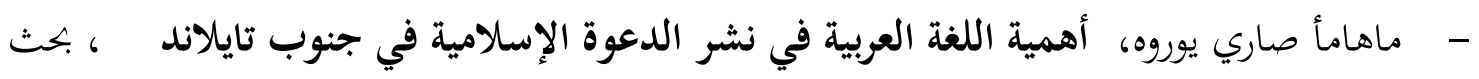

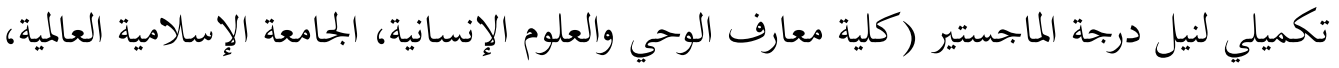
ماليزيا، 2000م)

- عدد من المؤلفين، دراسة عن نخبة المفكرين الملايويين ، (الجامعة الإسلامية العالمية ماليزيا، ط1 10 .) (2003

- - عبد الغني يعقوب، من معالم التاريخ السياسي والعلمي الإسلامي في فطاني دار السلام ، بحلة التجديد (الجامعة الإسلامية العالمية، ماليزيا، العدد 20، السنة العاشرة، 2006م). - - عبد القادر بن إسماعيل السنوي الفطاني، مصباح الغلام بشرح إيضاح المرام لتحقيق سبل السلام

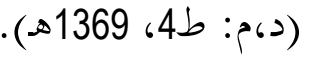

- - موان أحمد بن محمد زين الفطاني، كتاب أبنية الأسماء والأفعال (ويليه الرسالة الفطانية في علم

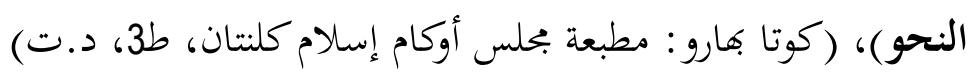

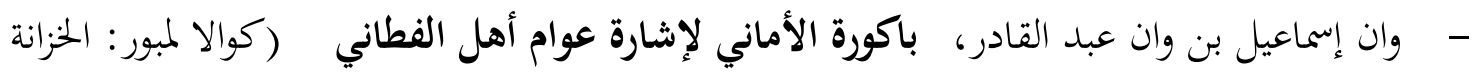

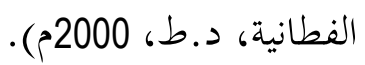

- وان إسماعيل بن عبد القادر الفطاني، تبصرة الأداني بألحان باكورة الأماني (فطاني: مطبعة فطاني

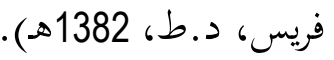
مقابلة شخصية مع الشيخ عبد الكريم بن حسب الله (شيخ المدرسة الإيمانية الدالوية الفطانية حالياً) في بيته، تاريخ 1 ديسمبر 2008م. - - مقابلة شخصية مع الشيخ إسماعيل بن حاج عبد الرحمن (شيخ مدرسة معيار العلوم حالياً) في بيته، تاريخ 23 إبريل 2009م.

Ahmad Fathy,2002,UlamaBesar Dari Patani, (Bangi: UniversitiKebangsaanMalaysia).

Ahmad Fathy, PengatarSejarahFatani, (KotaBharu: PustakaAman Press).

Ahmad Fathy, 2008,SumbanganUlamaPatani di dalamPendidikan Islam (Kertaskerjadibentang di Universiti Islam Yala).

Ahmad Fathy, 1996, MajalahPengasuh, Bil 541.

Ahmad Omar Chapakia, 2000, Politik Thai Dan Masyarakat Islam Di Selatan Thailand, (Pustaka Darussalam). 
Ismail CheDaud,Tokoh- TokohUlamaSemenanjungMelayu(2), (MajlisUgama Islam Dan AdatlstiadatMelayu Kelantan)

Wan Mohd. Shaghir, 2005, Sheikh Ahmad Al-FathaniPemikirAgungMelayudan Islam, (Kuala Lumpur: KhazanahFathaniyah, Cetakan1, jilid2)

WanMohdShaghir Abdullah, 2005,WacanaSyeikh Ahmad Al- Fahani, PemikirAgungMelayudan Islam(PersatuanPengkajianKhazanahKlasik Nusantara). 